\title{
Attribution of yield change for rice-wheat rotation system in China to climate change, cultivars and agronomic management in the past three decades
}

\author{
Huizi Bai ${ }^{1,2} \cdot$ Fulu Tao ${ }^{1,5}$ - Dengpan $\mathrm{Xiao}^{3}$. \\ Fengshan Liu ${ }^{4} \cdot$ He Zhang ${ }^{1,2}$
}

Received: 28 July 2015 / Accepted: 29 November 2015 /Published online: 4 December 2015

(C) Springer Science+Business Media Dordrecht 2015

\begin{abstract}
Using the detailed field experiment data from 1981 to 2009 at four representative agro-meteorological experiment stations in China, along with the Agricultural Production System Simulator (APSIM) rice-wheat model, we evaluated the impact of sowing/transplanting date on phenology and yield of rice-wheat rotation system (RWRS). We also disentangled the contributions of climate change, modern cultivars, sowing/ transplanting density and fertilization management, as well as changes in each climate variables, to yield change in RWRS, in the past three decades. We found that change in sowing/transplanting date did not significantly affect rice and wheat yield in RWRS, although alleviated the negative impact of climate change to some extent. From 1981 to 2009 , climate change jointly caused rice and wheat yield change by -17.4 to $1.5 \%$, of which increase in temperature reduced yield by $0.0-5.8 \%$ and decrease in solar radiation reduced it by $1.5-8.7 \%$. Cultivars renewal, modern sowing/transplanting density and fertilization management contributed to yield change by $14.4-27.2,-4.7--0.1$ and $2.3-$ $22.2 \%$, respectively. Our findings highlight that modern cultivars and agronomic management compensated the negative impacts of climate change and played key roles in yield increase in the past three decades.
\end{abstract}

Fulu Tao

taofl@igsnrr.ac.cn

1 Key Laboratory of Land Surface Pattern and Simulation, Institute of Geographical Sciences and Natural Resources Research, Chinese Academy of Sciences, Beijing 100101, China

2 University of Chinese Academy of Sciences, Beijing 100049, China

3 Institute of Geographical Sciences, Hebei Academy of Sciences, Shijiazhuang, Hebei 050011, China

4 Juncao Research Institute, Fujian Agriculture and Forestry University, Fuzhou, Fujian 350002, China

5 Natural Resources Institute Finland (Luke), FI-01301 Vantaa, Finland 


\section{Introduction}

Rice and wheat are two vital cereal crops in China, accounting for $58.9 \%$ (325.5 billion $\mathrm{kg}$ ) of the total cereal production in 2013 (http://www.stats.gov.cn). However, the growth rates of rice and wheat yields have become stagnated in some major production areas of China since 2000 (Wei et al. 2015). The stagnation of crop yield has also documented in South Asia and Northern Europe (Timsina and Humphreys 2006; Wiesmeier et al. 2015). The slowdown in crop productivity growth has raised concerns on the long-term sustainability of intensive rice and wheat production system. The roles of genotype, agronomic management and climate change in the yield stagnation need to be investigated to seek the sustainable development pathway for the cropping system.

Several studies documented that increase in temperature since 1980s had reduced crop yields by shortening crop growth duration and aggravating heat/water stresses (Liu et al. 2012; Tao et al. 2012a; Lobell et al. 2013; Xiong et al. 2014). Decrease in solar radiation had reduced crop yield by reducing photosysthesis rate and biomass accumulation (Sheehy et al. 2006; Zhang et al. 2010). On the other hand, improvement in crop cultivars and agronomic management practices had alleviated the negative impacts of climate change and increased crop yields (Zhang et al. 2013; Xiao and Tao 2014). The interactions between genotype, agronomic management and climate change were quite complicated and differed substantially between regions and cropping systems (Tao et al. 2014). In order to accelerate understanding of climate change impacts and develop adaptation options, it is necessary to disentangle the contributions of climate change, cultivars renewal and modern agronomic management, as well as change in each climate variables, to change in crop yield.

Most of previous studies focus on the mono-cropping system, although crop rotation system dominates at some areas. The rice-wheat rotation system (RWRS) is one of major cropping systems in eastern China (Fig. 1). In this study, using the detailed field experiment data on RWRS from 1981 to 2009 at four representative stations, together with the Agricultural Production System Simulator (APSIM) rice-wheat model, we aim (1) to evaluate the impact of sowing/transplanting date on phenology and yield of rice and wheat in RWRS; (2) to disentangle the contributions of climate change, modern cultivars, sowing/transplanting density and fertilization management, (3) as well as change in each climate variable, to yield change of RWRS in the past three decades.

\section{Materials and methods}

\subsection{Study sites, climate and crop data}

The study region includes Jiangsu and Anhui provinces, which is one of the major agricultural production regions in China. RWRS is the dominant cropping system in the region. The four agro-meteorological experiment stations, including Hefei and Shouxian stations in Anhui province and Kunshan and Xuzhou stations in Jiangsu province, were selected in this study (Fig. 1).

Daily weather data at the four stations from 1980 to 2010 , including minimum and maximum temperature, sunshine hours and precipitation, were obtained from the Chinese Meteorological Administration (CMA). The daily solar radiation was calculated from sunshine hours using the empirical Angstrom function (Prescott 1940). 


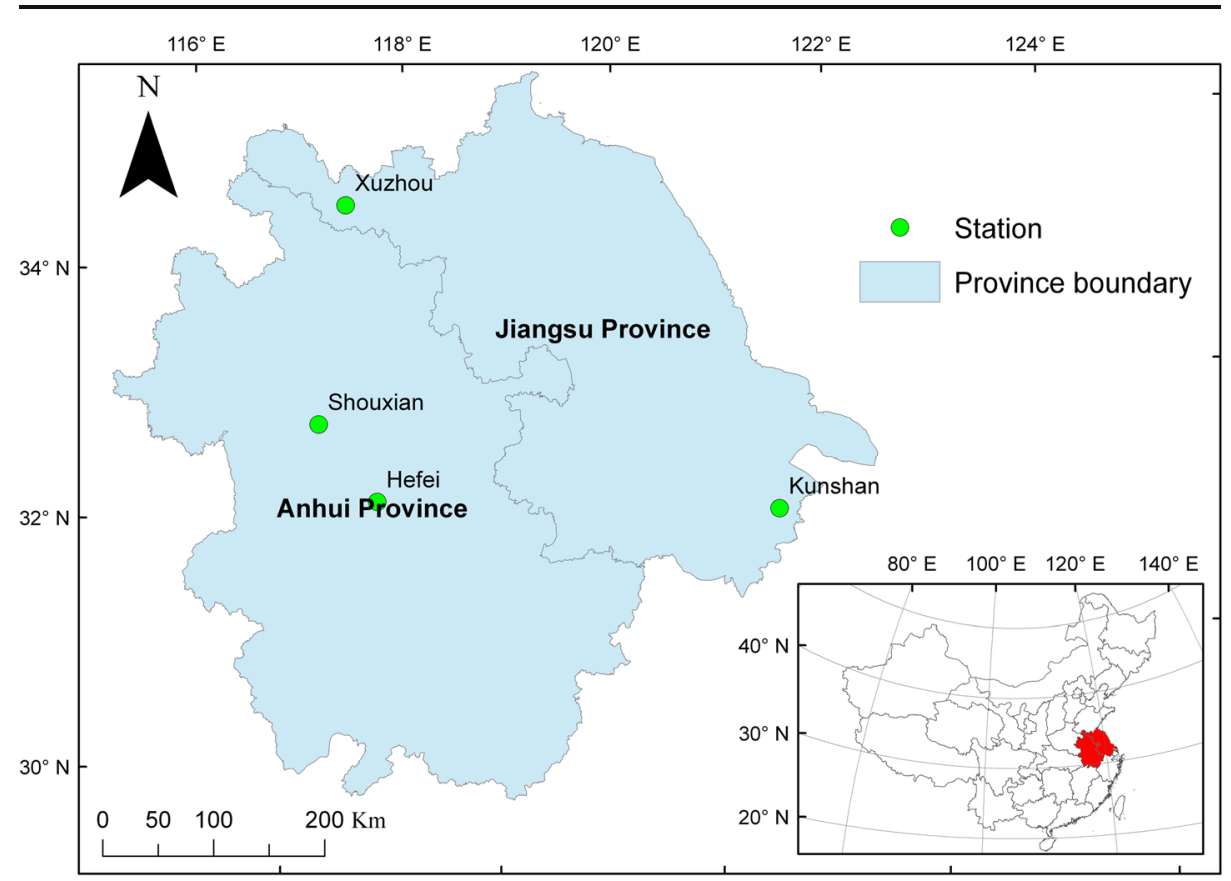

Fig. 1 Location of the four agro-meteorological experiment stations in this study

Field experiment data for RWRS in the four agro-meteorological experiment stations during 1981-2009, including crop phenology, cultivar type, yield, yield components and management practices, were obtained from CMA. In the study region, continuous flood irrigation was applied to rice, although wheat was rain-fed. In order to evaluate the contributions of cultivars renewal and modern agronomic management practice to yield change, representative cultivars, sowing/transplanting density and fertilization management practices for the period of 19811989 (80s) and 2005-2009 (00s) were, respectively, selected at each station (Table 1), based on the long term field experiment data.

\subsection{APSIM rice-wheat rotation system model}

APSIM model simulates crop growth/development, yield, soil water and nutrient dynamic for single crop or crop rotations in response to changes in climate and management conditions (Keating et al. 2003). APSIM rice-wheat rotation system model consists of two sub-models: APSIM-oryza model and APSIM-wheat model, which can simulate flooding condition for rice growth and drought conditions for wheat growth. APSIM model has been widely applied to simulate agricultural system in different regions of the world, including China (e.g., Wang et al. 2012; Liu et al. 2013; Xiao and Tao 2014).

\subsection{Modelling the impact of sowing/transplanting date on phenology and yield}

Two groups of simulations were conducted from 1981 to 2009 to investigate the impact of sowing/transplanting date on phenology and yield of RWRS. The first group of simulations was conducted with the single cultivar-80s, the observed sowing and 


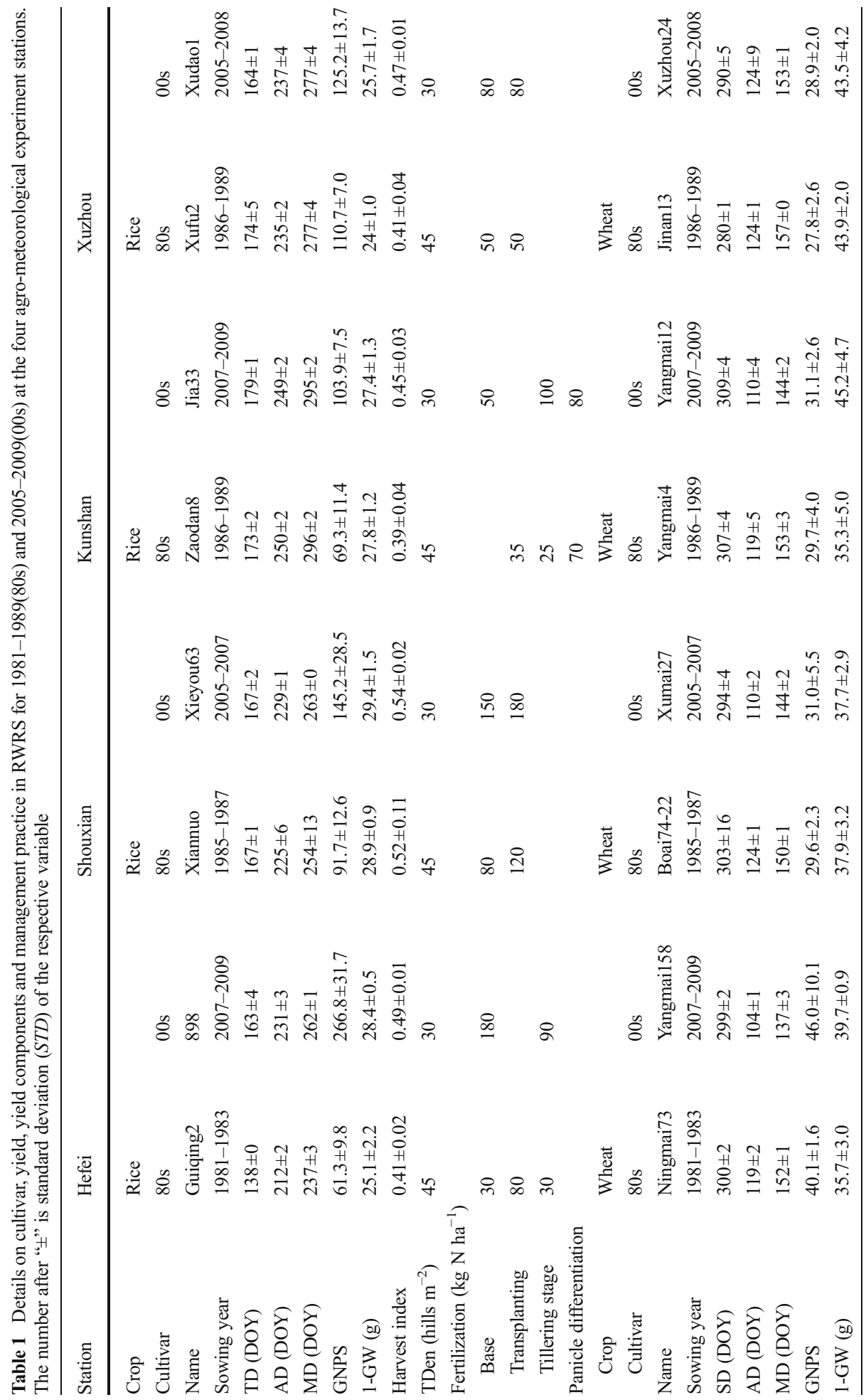




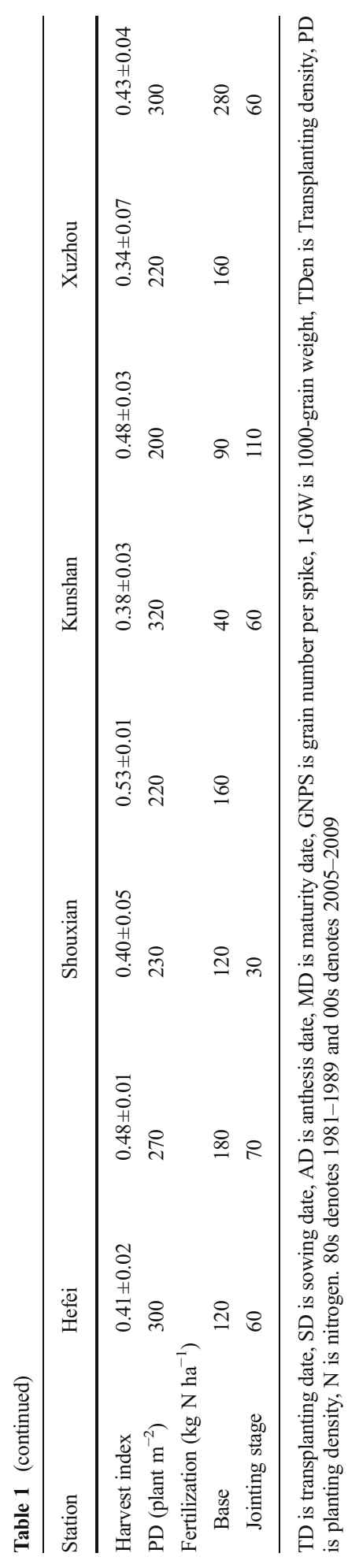


transplanting date for rice and observed sowing date for wheat in 1981 at each station. Because of cultivar and sowing/transplanting date were fixed in the simulations, the simulated changes in phenology and yield were affected only by climate change. The second group of simulations was conducted with the single cultivar-80s too, but with the observed sowing and transplanting date for rice and the observed sowing date for wheat in each year at each station. The impact of sowing/transplanting date change on phenology and yield of RWRS was investigated by comparing the results from the two groups of simulations.

\subsection{Disentangling the impact of change in each climate variable on yield}

At each station, to investigate the impacts of changes in all the climate variables including temperature, precipitation and solar radiation on yield of RWRS, the model was run with observed daily temperature, precipitation and solar radiation data from 1981 to 2009. Then, the impacts of changes in all the climate variables on yield were estimated by computing annual change of the simulated yields from 1981 to 2009. To disentangle the impact of change in temperature on crop yield, the model was firstly run from 1981 to 2009 with observed daily temperature data from 1981 to 2009 and the observed daily solar radiation and precipitation data in 1981 . The process was repeated for 29 times by replacing the inputs for daily solar radiation and precipitation data using observed daily data in each individual year from 1982 to 2009 , resulted in totally 29 years $\times 29$ times $=841$ simulations. Then, the impact of change in temperature on crop yield were estimated by computing annual change of simulated yields from 1981 to 2009, based on the total 841 simulated results. Likewise, the impact of change in solar radiation on crop yield was estimated. Because there was no significant trend in precipitation during the study period, the impact of change in precipitation on yield were not investigated.

\subsection{Quantifying the contributions of crop cultivars, sowing/transplanting density and fertilization to yield change}

To evaluate the contributions of cultivars, sowing/transplanting density and fertilization management to yield change in RWRS in the past three decades, five sets of modeling experiments (i.e., E1, E2, E3, E4 and E5) were designed (Table 2). The impacts of cultivars, sowing/transplanting density and fertilization management on crop yield were disentangled by comparing the results from different modeling experiments, using the following equations:

Table 2 Five modeling experiments (i.e., E1, E2, E3, E4 and E5) designed to investigate the individual contribution of cultivars renewal, modern sowing/transplanting density and new fertilization to yield change of RWRS. 80s and 00s denote the period of 1981-1989 and 2005-2009, respectively

\begin{tabular}{llll}
\hline Experiment & Cultivar & Sowing/transplanting density & Fertilization \\
\hline E1 & $80 \mathrm{~s}$ & $80 \mathrm{~s}$ & $80 \mathrm{~s}$ \\
E2 & $00 \mathrm{~s}$ & $80 \mathrm{~s}$ & $80 \mathrm{~s}$ \\
E3 & $80 \mathrm{~s}$ & $00 \mathrm{~s}$ & $80 \mathrm{~s}$ \\
E4 & $80 \mathrm{~s}$ & $80 \mathrm{~s}$ & $00 \mathrm{~s}$ \\
E5 & $00 \mathrm{~s}$ & $00 \mathrm{~s}$ & $00 \mathrm{~s}$ \\
\hline
\end{tabular}




$$
\begin{aligned}
& \mathrm{C}_{\mathrm{Cul}}=\frac{\mathrm{Y}_{\mathrm{E} 2}-\mathrm{Y}_{\mathrm{E} 1}}{\mathrm{Y}_{\mathrm{E} 1}} \times 100 \% \\
& \mathrm{C}_{\mathrm{Den}}=\frac{\mathrm{Y}_{\mathrm{E} 3}-\mathrm{Y}_{\mathrm{E} 1}}{\mathrm{Y}_{\mathrm{E} 1}} \times 100 \% \\
& \mathrm{C}_{\mathrm{Fer}}=\frac{\mathrm{Y}_{\mathrm{E} 4}-\mathrm{Y}_{\mathrm{E} 1}}{\mathrm{Y}_{\mathrm{E} 1}} \times 100 \% \\
& \mathrm{C}_{\mathrm{CDF}}=\frac{\mathrm{Y}_{\mathrm{E} 5}-\mathrm{Y}_{\mathrm{E} 1}}{\mathrm{Y}_{\mathrm{E} 1}} \times 100 \%
\end{aligned}
$$

Where $\mathrm{C}_{\mathrm{Cul}}, \mathrm{C}_{\mathrm{Den}}$ and $\mathrm{C}_{\mathrm{Fer}}$ are the contributions of cultivars renewal, modern sowing/ transplanting density management, modern fertilization management to yield change, respectively. $\mathrm{C}_{\mathrm{CDF}}$ is the joint contributions of cultivars renewal, modern sowing/transplanting density and fertilization management to yield. $\mathrm{Y}_{\mathrm{E} 1}, \mathrm{Y}_{\mathrm{E} 2}, \mathrm{Y}_{\mathrm{E} 3}, \mathrm{Y}_{\mathrm{E} 4}$ and $\mathrm{Y}_{\mathrm{E} 5}$ are the simulated yields by the modeling experiments E1, E2, E3, E4 and E5, respectively.

\section{Results}

\subsection{Changes in crop cultivars, phenology and yield, and agronomic management, based on field experiment data from 1981 to 2009}

According to the field experiment data from 1981 to 2009, for rice, the duration from transplanting to maturity of cultivar-00s was longer than that of cultivar-80s at all the stations except Kunshan (Table 1). And the duration from anthesis to maturity of cultivar-00s was longer than that of cultivar-80s at all the stations except Xuzhou. For wheat, the duration from sowing to maturity of cultivar-00s was shorter than that of cultivar-80s at all the stations except Shouxian. However, the duration from anthesis to maturity of cultivar-00s was longer than that of cultivar-80s at all the stations except Xuzhou. For both rice and wheat, the grain number per spike, HI and yields of cultivar-00s were larger than those of cultivar-80s at all the four stations (Table 1). In term of agronomic management, from 1981 to 2009, rice transplanting density became lower at all the four stations, and wheat sowing density became lower too at all the stations except Xuzhou. The fertilizer application rate increased substantially for both rice and wheat at all the four stations (Table 1).

\subsection{Calibration and validation of APSIM rice-wheat model using observed experiment data}

At each station, the APSIM rice-wheat model was calibrated and validated for cultivar-80s and cultivar-00s based on the field experiment data during 1981-1989 and during 2005-2009, respectively. The cultivar-specific parameters required to run APSIM-oryza model include development rates during juvenile phase, photoperiod-sensitive phase, panicle development 
phase and reproductive phase, and photoperiod sensitivity. The cultivar-specific parameters required to run APSIM-wheat model include four parameters related to phenological development (i.e., tt_end_of_juvenile, Startgf_to_mat, Vern_sens, Photop_sens), and three parameters related to grain yield (i.e., Potential_grain_filling_rate, Grains_per_gram_stem, Max_grain_size).

The results showed that the simulated dates of anthesis and maturity were in good agreement with the observed dates for rice and wheat at all the four stations (Fig. 2). The difference between simulated and observed phenological dates for both crops was on average less than 5 days. The simulated yield also agreed well with observed yield for rice and wheat (Fig. 2). Compared with the observed yield, the relative error of the simulated yield was less than $15 \%$. Overall, APSIM rice-wheat model can simulate the phenological development and yield information in RWRS fairly well.

\subsection{Impact of sowing/transplanting date on phenology and yield of RWRS}

Due to climate warming, for rice, the simulated growth duration from sowing to anthesis decreased significantly by 1.0-1.6 days/decade at all the stations (Table 3), however the duration from anthesis to maturity had no significant change at all the stations except Kunshan. For wheat, the simulated growth duration from sowing to anthesis was shortened significantly by $4.0-5.5$ days/decade, and the duration from anthesis to maturity had no significant change at all the stations.

During the study period, the observed rice sowing and transplanting dates were delayed significantly at Hefei and Kunshan (Table 3). As a result, rice growth duration from sowing to anthesis was slightly shortened, but growth duration from anthesis to maturity was slightly prolonged. The observed wheat sowing date was delayed significantly $(P<0.01)$ only at Xuzhou, which shortened slightly the growth duration from sowing to anthesis, and from anthesis to maturity.

As shown in Fig. 3, shifts in sowing/transplanting date had no significant impact on rice and wheat yield. Shifts in transplanting date increased rice yield slightly at all the stations. Late sowing of wheat reduced slightly wheat yield at Xuzhou.

\subsection{Impacts of different climate variables on rice and wheat yield from 1981 to 2009}

Trends in different climatic variables at the four stations from 1981 to 2009 were shown in Table 4. Annual mean maximum and minimum temperature increased significantly at all the four stations and annual mean solar radiation decreased significantly at Hefei, Shouxian and Xuzhou stations. During both rice and wheat growth period, mean maximum and minimum temperature increased significantly at all the stations. Mean solar radiation decreased significantly at Hefei, Shouxian and Xuzhou during rice growth period, however changed slightly during wheat growth period (Table 4).

In the past three decades, increase in temperature reduced the total yields of RWRS by $0.1-$ $0.3 \%$ per year at all stations for cultivar-80s, and reduced it at Kunshan and Xuzhou for cultivar-00s (Table 5). For both cultivar-80s and cultivar-00s, decrease in solar radiation reduced the total yield of RWRS by $0-0.5 \%$ per year at Hefei, Shouxian and Xuzhou, and increase in solar radiation increased it significantly $(P<0.01)$ by $0.2-0.3 \%$ per year at Kunshan. For cultivar-80s, changes in all the climatic variables jointly reduced the total yield of RWRS by $0.4-0.9 \%$ per year at Hefei, Shouxian and Xuzhou, however increased it by 

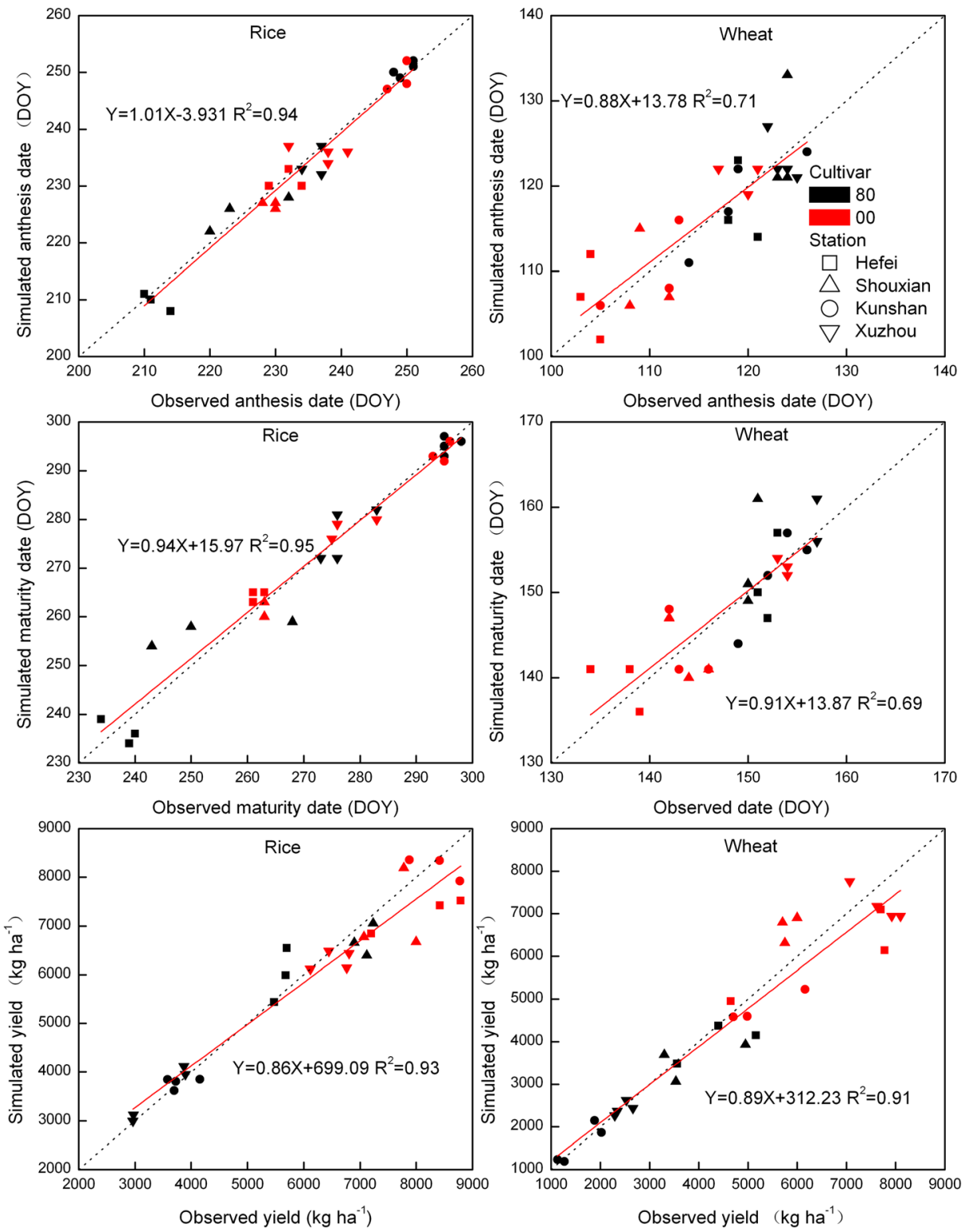

Fig. 2 Validation of the APSIM rice-wheat model simulations on anthesis date, maturity date and yield for RWRS at the study stations

$0.1 \%$ per year at Kunshan. For cultivar-00s, changes in all the climatic variables jointly reduced the total yield of RWRS by $0.0-0.3 \%$ per year at Hefei, Kunshan and Xuzhou, however increased it by $0.2 \%$ per year at Shouxian.

Increase in temperature reduced rice yield at all stations for cultivar-80s, however, had insignificant impact on yield for cultivar-00s. Decrease in solar radiation reduced rice yield for cultivar-80s significantly $(P<0.05)$ at Hefei, Shouxian and Xuzhou, and reduced it for cultivar00 s significantly only at Shouxian $(P<0.05)$. Increase in solar radiation increased rice yield 
Table 3 Trends (days/decade) in observed and simulated durations of key development stages at each station

\begin{tabular}{|c|c|c|c|c|c|c|c|c|c|}
\hline Crop & Station & SD & TD & SA1 & SA2 & AM1 & AM2 & SM1 & SM2 \\
\hline \multicolumn{10}{|l|}{ Rice } \\
\hline & Hefei & $6.55^{* *}$ & $5.39 *$ & $-1.55^{* *}$ & $-2.41 * *$ & 0 & 0.31 & $-1.54 * *$ & $-2.1 * *$ \\
\hline & Shouxian & 0.96 & -0.78 & $-1.35^{* *}$ & $-2.02 * *$ & -0.18 & -0.35 & $-1.53 *$ & $-2.37^{*}$ \\
\hline & Kunshan & $5.33 * *$ & 2.23 & $-1.24 *$ & $-2.98 * *$ & $-4.02 * *$ & $-1.64 *$ & $-5.26^{* *}$ & $-4.62 * *$ \\
\hline & Xuzhou & -1.98 & -2.77 & $-1.03 *$ & -1.10 & -0.99 & $-1.49 *$ & $-2.02 *$ & $-2.59^{*}$ \\
\hline \multicolumn{10}{|l|}{ Wheat } \\
\hline & Hefei & -1.13 & & $-5.52 * *$ & $-4.95 * *$ & 0.35 & 0.53 & $-5.17 * *$ & $-4.41 * *$ \\
\hline & Shouxian & -1.80 & & $-4.03^{* *}$ & -3.29 & -0.07 & 0.32 & $-3.96 * *$ & -2.93 \\
\hline & Kunshan & -0.19 & & $-3.93 *$ & -4.20 & -0.24 & -0.14 & $-4.18 * *$ & $-4.35^{*}$ \\
\hline & Xuzhou & $6.15^{* *}$ & & $-4.89 * *$ & $-6.3 * *$ & 0.27 & -0.42 & $-4.63 * *$ & $-6.73 * *$ \\
\hline
\end{tabular}

*Significant at $P<0.05$ and $* *$ significant at $P<0.01$. SD is sowing date. TD is transplanting date. SA, AM, SM are the duration from sowing to anthesis, anthesis to maturity and sowing to maturity, respectively. 1,2 denote the simulated durations with sowing/transplanting date in 1981 and the simulated durations with recorded sowing/ transplanting dates, respectively

slightly at Kunshan for both cultivar-80s and cultivar-00s. Changes in all the climatic variables jointly reduced rice yield for cultivar-80s significantly $(P<0.01)$ by $0.8-1.0 \%$ per year at Hefei, Shouxian and Xuzhou, and reduced it for cultivar-00s significantly only at Hefei by $0.4 \%(P<0.05)$. Rice cultivar-00s was more resilient to high temperature and low solar radiation than cultivar- 80 s.

Increase in temperature reduced wheat yield at Hefei, Kunshan and Xuzhou stations with cultivar-80s, and reduced it at Kunshan and Xuzhou with cultivar-00s (Table 5). For both cultivar-80s and cultivar-00s, increase in solar radiation increased wheat yield significantly at Shouxian and Kunshan stations, however decrease in solar radiation reduced it slightly at Hefei and Xuzhou stations. Changes in all the climatic variables jointly reduced wheat yield by $0.4-0.7 \%$ per year at Hefei and Xuzhou while increased it by $0.3-0.5 \%$ per year at Shouxian and Kunshan, with cultivar-80s. By contrast, with cultivar-00s, changes in all the climatic variables jointly increased wheat yield at all stations except Xuzhou. Wheat cultivar-00s was more resilient to climate change in the past three decades than cultivar-80s.

Fig. 3 Impacts of sowing/ transplanting date on yield of RWRS. Yield trends denote linear trends in the differences between the simulated yields with fixed sowing/transplanting date and observed sowing/transplanting date from 1981 to 2009 . * denotes significant at $P<0.05$ and $* *$ denotes significant at $P<0.01$

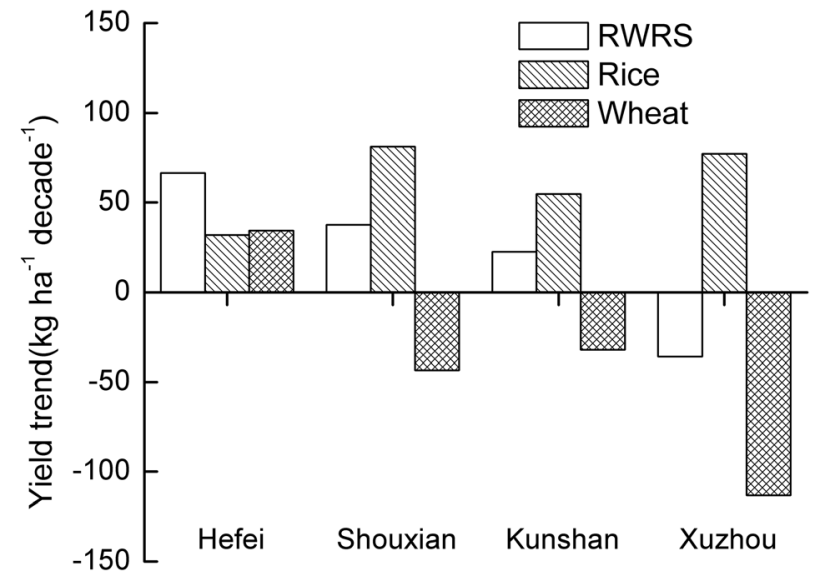


Table 4 Trends in maximum temperature (Tmax), minimum temperature (Tmin), solar radiation (Rad) and precipitation (Prec) during the year, during rice growth period (RGP) and during wheat growth period (WGP) at the four stations for 1981-2009

\begin{tabular}{|c|c|c|c|c|c|c|c|c|c|}
\hline \multirow[t]{2}{*}{ Station } & \multirow[t]{2}{*}{ Period } & \multicolumn{2}{|l|}{ Tmax } & \multicolumn{2}{|l|}{ Tmin } & \multicolumn{2}{|l|}{$\operatorname{Rad}$} & \multicolumn{2}{|l|}{ Prec } \\
\hline & & $\begin{array}{l}\text { Mean } \\
\left({ }^{\circ} \mathrm{C}\right)\end{array}$ & $\begin{array}{l}\text { Trend } \\
\left({ }^{\circ} \mathrm{C} \text { decade }{ }^{-1}\right)\end{array}$ & $\begin{array}{l}\text { Mean } \\
\left({ }^{\circ} \mathrm{C}\right)\end{array}$ & $\begin{array}{l}\text { Trend } \\
\left({ }^{\circ} \mathrm{C} \text { decade }{ }^{-1}\right)\end{array}$ & $\begin{array}{l}\text { Mean } \\
\left(\mathrm{MJm}^{-2}\right)\end{array}$ & $\begin{array}{l}\text { Trend } \\
\left(\mathrm{MJm}^{-2} \text { decade }^{-1}\right)\end{array}$ & $\begin{array}{l}\text { Mean } \\
(\mathrm{mm})\end{array}$ & $\begin{array}{l}\text { Trend } \\
\left(\mathrm{mm} \mathrm{decade}^{-1}\right)\end{array}$ \\
\hline \multirow[t]{3}{*}{ Hefei } & Annual & 21.8 & $0.63 * *$ & 13.8 & $0.58 * *$ & 11.9 & $-0.31 * *$ & 995.5 & -4.9 \\
\hline & RGP & 28.7 & $0.60 * *$ & 20.9 & $0.62 * *$ & 13.6 & $-0.50 * *$ & 557.8 & -33.7 \\
\hline & WGP & 14.9 & $0.67 * *$ & 6.6 & $0.53 * *$ & 10.3 & -0.13 & 437.7 & 28.8 \\
\hline \multirow[t]{3}{*}{ Shouxian } & Annual & 21.3 & $0.47 * *$ & 12.3 & $0.46^{* *}$ & 12.6 & $-0.21^{*}$ & 937.6 & -17.3 \\
\hline & RGP & 28.2 & $0.39 * *$ & 19.9 & $0.38 * *$ & 14.6 & $-0.50^{*}$ & 614.9 & -32.5 \\
\hline & WGP & 14.5 & $0.56 * *$ & 4.7 & $0.53 * *$ & 11.0 & 0.08 & 322.7 & 15.2 \\
\hline \multirow[t]{3}{*}{ Kunshan } & Annual & 21.8 & $0.55 * *$ & 14.9 & $0.84 * *$ & 12.3 & 0.15 & 1196.3 & -3.5 \\
\hline & RGP & 28.5 & $0.55^{* *}$ & 22.0 & $0.85^{* *}$ & 14.2 & 0.10 & 700.3 & -13.4 \\
\hline & WGP & 15.0 & $0.56 * *$ & 7.7 & $0.83^{* *}$ & 10.4 & 0.20 & 496.0 & 9.9 \\
\hline \multirow[t]{3}{*}{ Xuzhou } & Annual & 21.1 & $0.30 * *$ & 11.8 & $0.65 * *$ & 13.6 & $-0.39 * *$ & 852.1 & 27.9 \\
\hline & RGP & 28.2 & 0.24 & 19.4 & $0.64 * *$ & 15.3 & $-0.66^{*}$ & 628.3 & 30.0 \\
\hline & WGP & 13.9 & $0.36^{*}$ & 4.3 & $0.66^{* *}$ & 11.9 & -0.12 & 223.8 & -1.7 \\
\hline
\end{tabular}

* Significant at $P<0.05$ and ** significant at $P<0.01$

\subsection{Contributions of crop cultivars, modern sowing/transplanting density and modern fertilization to yield change during 1981-2009}

As shown in Table 6, from 1981 to 2009, cultivars renewal boosted the total yield of RWRS, rice yield and wheat yield by 14.4-27.2, 19.3-33.4 and 6.5-27.8 \%, respectively. Modern sowing/transplanting density management changed the total yield of RWRS, rice yield and wheat yield by $-4.7--0.1,-4.2-0.1$ and $-13.5-0.2 \%$, respectively. Modern fertilization management boosted the total yield of RWRS, rice yield and wheat yield by $2.3-22.2,0.5-$ 24.9 and 5.8-14.8 \%, respectively. Cultivars renewal, modern sowing/transplanting density and fertilization management jointly increased the total yield of RWRS, rice yield and wheat yield by $34.3-61.7,26.0-62.5$ and $45.6-63.3 \%$, respectively.

\section{Discussions}

\subsection{Impacts of sowing/transplanting date on phenology and yield of RWRS in the past three decades}

Shift in sowing/transplanting date is an effective adaptation strategy for RWRS to deal with ongoing climate change condition (Tao et al. 2012b). Proper late sowing and late transplanting can extend slightly rice growth duration from anthesis to maturity and increase rice yield. However, late sowing of rice may result in delayed sowing of wheat, which may reduce wheat yield because the period from anthesis to maturity may be increasingly subjected to high temperature and wheat grain filling duration may be shortened.

For double cropping system, the total yield of the whole cropping system should be considered rather than the yield of individual crop. In the North China Plain, late sowing of 
winter wheat and late harvesting of maize increased the total yield of the wheat-maize system by $4-6 \%$ (Wang et al. 2012). In this study, at Xuzhou, slight advance in rice sowing and transplanting date increased rice yield, however significant delay in wheat sowing reduced the total yield of RWRS. Therefore, the phenological dynamic should be optimized to identify the optimal sowing/transplanting date for rice and wheat in RWRS.

\subsection{Impacts of different climate variables on yield of RWRS in the past three decades}

Due to the diverse climate conditions among stations, as well as the different sensitivity of crop yields to each climate variable, the impacts of each climate variable on yield of RWRS were also different (Fig. 4). In the past three decades, significant increase in temperature reduced both rice and wheat yield, in particular for cultivar-80s, mainly because it accelerated the crop development rate, reduced crop growth duration (Table 3) and biomass accumulation (Tao et al. 2012a). Modern cultivar had longer growth durations, consequently more resilient to climate warming. Decrease in solar radiation reduced rice yield at Hefei, Shouxian and Xuzhou and reduced wheat yield at Hefei and Xuzhou. By contrast, increase in solar radiation increased rice yield at Kunshan and wheat yield at Shouxian and Kunshan.

Table 5 Impacts of all climatic variables $\left(\mathrm{C}_{\mathrm{All}}\right)$, temperature $\left(\mathrm{C}_{\mathrm{Temp}}\right)$, and solar radiation $\left(\mathrm{C}_{\mathrm{Rad}}\right)$ on yield trends $\left(\mathrm{kg} \mathrm{ha}^{-1}\right.$ year $\left.^{-1}\right)$ for two cultivars during 1981-2009 at each station. The numbers in parenthesis are the corresponding values in percentage

\begin{tabular}{|c|c|c|c|c|c|}
\hline & & Hefei & Shouxian & Kunshan & Xuzhou \\
\hline \multicolumn{6}{|l|}{ RWRS } \\
\hline \multirow[t]{3}{*}{ Cultivar-80s } & $\mathrm{C}_{\mathrm{All}}$ & $-58.3 * *(-0.6 \%)$ & $-37.8 *(-0.4 \%)$ & $6.0(0.1 \%)$ & $-61.0 * *(-0.9 \%)$ \\
\hline & $\mathrm{C}_{\mathrm{Temp}}$ & $-16.8(-0.2 \%)$ & $-7.6(-0.1 \%)$ & $-7.9(-0.1 \%)$ & $-22.3 * *(-0.3 \%)$ \\
\hline & $\mathrm{C}_{\mathrm{Rad}}$ & $-34.5 *(-0.4 \%)$ & $-12.2(-0.1 \%)$ & $11.2 *(0.2 \%)$ & $-35.7 * *(-0.5 \%)$ \\
\hline \multirow[t]{3}{*}{ Cultivar-00s } & $\mathrm{C}_{\mathrm{All}}$ & $-24.7(-0.2 \%)$ & $23.3(0.2 \%)$ & $-2.3(0 \%)$ & $-23.4(-0.3 \%)$ \\
\hline & $\mathrm{C}_{\text {Temp }}$ & $8.4(0.1 \%)$ & $9.8(0.1 \%)$ & $-26.2 * *(-0.3 \%)$ & $-1.1(0 \%)$ \\
\hline & $\mathrm{C}_{\mathrm{Rad}}$ & $-26.4(-0.2 \%)$ & $-3.3(0 \%)$ & $23.9 * *(0.3 \%)$ & $-1.4(0 \%)$ \\
\hline \multicolumn{6}{|l|}{ Rice } \\
\hline \multirow[t]{3}{*}{ Cultivar-80s } & $\mathrm{C}_{\mathrm{All}}$ & $-44.0 * *(-0.8 \%)$ & $-57.2 * *(-0.9 \%)$ & $-0.5(0 \%)$ & $-42.3 * *(-1.0 \%)$ \\
\hline & $\mathrm{C}_{\mathrm{Temp}}$ & $-6.5(-0.1 \%)$ & $-8.3(-0.1 \%)$ & $-2.1(-0.1 \%)$ & $-14.0 *(-0.4 \%)$ \\
\hline & $\mathrm{C}_{\mathrm{Rad}}$ & $-32.9 *(-0.6 \%)$ & $-42.1 *(-0.7 \%)$ & $2.1(0.1 \%)$ & $-28.2 * *(-0.7 \%)$ \\
\hline \multirow[t]{3}{*}{ Cultivar-00s } & $\mathrm{C}_{\mathrm{All}}$ & $-27.4 *(-0.4 \%)$ & $-27.8(-0.4 \%)$ & $-3.7(0 \%)$ & $7.4(0.1 \%)$ \\
\hline & $\mathrm{C}_{\text {Temp }}$ & $2.9(0 \%)$ & $3.6(0 \%)$ & $-5.7(-0.1 \%)$ & $2.6(0.1 \%)$ \\
\hline & $\mathrm{C}_{\mathrm{Rad}}$ & $-24.3(-0.3 \%)$ & $-34.0 *(-0.5 \%)$ & $2.3(0.1 \%)$ & $1.8(0 \%)$ \\
\hline \multicolumn{6}{|l|}{ Wheat } \\
\hline \multirow[t]{3}{*}{ Cultivar-80s } & $\mathrm{C}_{\mathrm{All}}$ & $-14.3(-0.4 \%)$ & $19.4 *(0.5 \%)$ & $6.5(0.3 \%)$ & $-18.7(-0.7 \%)$ \\
\hline & $\mathrm{C}_{\text {Temp }}$ & $-10.3 *(-0.3 \%)$ & $0.7(0 \%)$ & $-5.8(-0.3 \%)$ & $-8.4 * *(-0.3 \%)$ \\
\hline & $\mathrm{C}_{\mathrm{Rad}}$ & $-1.6(0 \%)$ & $29.9 *(0.8 \%)$ & $9.1 * *(0.5 \%)$ & $-7.5 * *(-0.3 \%)$ \\
\hline \multirow[t]{3}{*}{ Cultivar-00s } & $\mathrm{C}_{\mathrm{All}}$ & $2.7(0.1 \%)$ & $51.1 * *(1.2 \%)$ & $1.4(0 \%)$ & $-30.8(-0.9 \%)$ \\
\hline & $\mathrm{C}_{\mathrm{Temp}}$ & $5.5(0.1 \%)$ & $6.2(0.2 \%)$ & $-20.5 *(-0.7 \%)$ & $-3.7(-0.1 \%)$ \\
\hline & $\mathrm{C}_{\mathrm{Rad}}$ & $-2.1(0 \%)$ & $30.7 *(0.8 \%)$ & $21.6^{* *}(0.7 \%)$ & $-3.2(-0.1 \%)$ \\
\hline
\end{tabular}

* Significant at $P<0.05$ and ** significant at $P<0.01$ 
Table 6 Contributions $(\%)$ of cultivars renewal $\left(\mathrm{C}_{\mathrm{Cul}}\right)$, modern sowing/transplanting density $\left(\mathrm{C}_{\text {Den }}\right)$, and modern fertilization $\left(\mathrm{C}_{\mathrm{Fer}}\right)$ to yield change at each station during 1981-2009. $\mathrm{C}_{\mathrm{CDF}}$ denote the joint contributions of cultivars and management to yield change. The number after " \pm " is standard deviation (STD) of the corresponding values

\begin{tabular}{ccccc}
\hline Station & Hefei & Shouxian & Kunshan & Xuzhou \\
\hline RWRS & & & & \\
$\mathrm{C}_{\mathrm{Cul}}$ & $21.8 \pm 10.6$ & $14.4 \pm 7.2$ & $27.2 \pm 12.2$ & $26.5 \pm 9.7$ \\
$\mathrm{C}_{\text {Den }}$ & $-2.1 \pm 1.3$ & $-0.1 \pm 0.4$ & $-4.7 \pm 2.2$ & $-2.4 \pm 1.5$ \\
$\mathrm{C}_{\mathrm{Fer}}$ & $6.2 \pm 5.3$ & $2.3 \pm 3.0$ & $22.2 \pm 6.0$ & $14.3 \pm 8.3$ \\
$\mathrm{C}_{\mathrm{CDF}}$ & $49.9 \pm 11.7$ & $34.3 \pm 8.2$ & $49.2 \pm 29.1$ & $61.7 \pm 14.7$ \\
Rice & & & & \\
$\mathrm{C}_{\mathrm{Cul}}$ & $27.1 \pm 16.0$ & $19.3 \pm 9.5$ & $33.4 \pm 14.6$ & $25.6 \pm 12.7$ \\
$\mathrm{C}_{\text {Den }}$ & $-3.4 \pm 1.4$ & $0.1 \pm 0.7$ & $-1.3 \pm 0.6$ & $-4.2 \pm 1.9$ \\
$\mathrm{C}_{\mathrm{Fer}}$ & $6.6 \pm 3.8$ & $0.5 \pm 0.9$ & $24.9 \pm 2.6$ & $15.4 \pm 4.0$ \\
$\mathrm{C}_{\mathrm{CDF}}$ & $40.4 \pm 18.6$ & $26.0 \pm 9.2$ & $49.9 \pm 19.7$ & $62.5 \pm 10.2$ \\
$\mathrm{Wheat}$ & & & & \\
$\mathrm{C}_{\mathrm{Cul}}$ & $15.2 \pm 13.6$ & $6.5 \pm 14.1$ & $10.5 \pm 16.5$ & $27.8 \pm 14.7$ \\
$\mathrm{C}_{\mathrm{Den}}$ & $-0.3 \pm 2.2$ & $-0.2 \pm 0.8$ & $-13.5 \pm 8.4$ & $0.2 \pm 2.3$ \\
$\mathrm{C}_{\mathrm{Fer}}$ & $6.0 \pm 8.6$ & $5.8 \pm 7.9$ & $14.8 \pm 18.0$ & $11.5 \pm 10.0$ \\
$\mathrm{C}_{\mathrm{CDF}}$ & $63.3 \pm 18.9$ & $49.3 \pm 18.8$ & $45.6 \pm 21.8$ & $58.5 \pm 35.4$ \\
\hline
\end{tabular}

Significant increase in temperature, together with significant decrease in solar radiation, reduced rice yield significantly at Hefei, Shouxian and Xuzhou, as well as wheat yield at Hefei and Xuzhou. Significant increase in temperature, together with insignificant increase in solar radiation, increased rice yield at Kunshan, as well as wheat yield at Shouxian and Kunshan. The results implied that change in solar radiation played a more important role in affecting crop yield in comparison with other climate variables. The results are supported by some

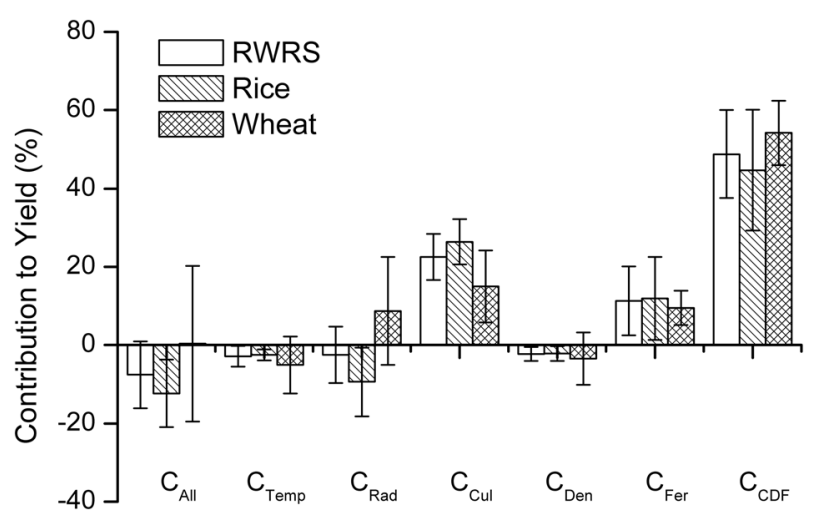

Fig. 4 Mean contributions of cultivars renewal, sowing/transplanting density, and fertilization and climate variables to yield change of RWRS across the four stations during 1981-2009. $C_{\mathrm{All}}, \mathrm{C}_{\mathrm{Temp}}, \mathrm{C}_{\mathrm{Rad}}, \mathrm{C}_{\mathrm{Cul}}, \mathrm{C}_{\text {Den }}$, $\mathrm{C}_{\mathrm{Fer}}$ denote the contribution of all climatic variables, temperature, and solar radiation, cultivars, sowing/ transplanting density and fertilization to yield change, respectively. $\mathrm{C}_{\mathrm{CDF}}$ denotes the combined contributions of cultivars and management to yield change 
previous studies based on both long term field experiment data and census data (Peng et al. 2004; Zhang et al. 2013; Tao et al. 2012a; Tao et al. 2014). which indicated that crop yield was positively correlated with solar radiation in this region. However, Liu et al. (2013) showed that climate change had a negative impact on rice yield at Kunshan from 1980s to 2000s. The disparity may be due to the different methods and data used in evaluating the impact of climate change on crop yield.

\subsection{Contributions of cultivars and management to yield of RWRS in the past three decades}

In this study, we found that from 1981 to 2009 cultivars renewal, modern fertilization management contributed substantially to yield increase in RWRS in the past three decades (Fig. 4). Cultivars renewal increased rice yields by $26.4 \%$ from 1981 to 2009 . Compared with old cultivars, modern cultivars were characterized by longer duration from anthesis to maturity, large number of grains and high HI for both rice and wheat. Cultivars renewal markedly increased crop yield and became more resilient to warmer climatic conditions. The findings are supported by some previous studies based on both field experiment data and model simulations (Tao et al. 2012b; Liu et al. 2013; Xiao and Tao 2014). For example, Tao et al (2012b) found wheat cultivars were being renewed to adapt to climate change. Liu et al. (2013) showed that cultivars renewal contributed to rice yields by about $21.7 \%$ in the Taihu region in Jiangsu province from 1980 s to 2000 s.

We found that impacts of modern sowing/transplanting density on yield of RWRS were small, and decrease in sowing/transplanting density reduced yield of RWRS. Improved fertilization management had contributed notably to crop yield increase over the past three decades in China. Chinese agriculture had intensified greatly inputs of chemical fertilizers since the early 1980s (Guo et al. 2010). but fertilization use efficiency decreased with application rate increasing (Peng et al. 2006). Consequently, the key to optimize trade-offs among yield, profit, and environmental protection is to achieve synchrony between fertilizer supply and crop demand without surplus or deficiency (Cassman et al. 2002). In addition, other improvements in agronomic management practices such as pest, disease and weed management, soil melioration and no-tillage contributed to yield increase too, which however were not accounted in this study. The results highlight that breeding new cultivars and optimizing agronomic management practices have a high potential to cope with future climate risk.

\section{Conclusions}

During the past three decades, modern cultivars and fertilization management contributed remarkably to yield increase in RWRS. Change in sowing/transplanting date did not significantly affect the total yield of RWRS, although shift in sowing/transplanting date alleviated the negative effect of climate change. Without adaptation measures, climate change, characterized by increase in temperature and decrease in solar radiation, could negatively affect the yield of RWRS during the study period.

To compensate the negative impacts of climate change, effective adaptation strategies should be developed, including breeding climate resilient crop cultivars and developing climate smart agronomic management. Climate resilient crop cultivars that have longer 
duration from anthesis to maturity, large number of grains and high $\mathrm{HI}$ for both rice and wheat are promising. Climate smart agronomic management should be developed, including optimal sowing/transplanting date, optimal planting/transplanting density, efficient cultivations and fertilization management.

Acknowledgments This study was supported by the National Natural Science Foundation of China (Nos. 41571088 and 31561143003). Funding support by FACCE MACSUR project through the Finnish Ministry of Agriculture and Forestry and by Luke through the strategic MODAGS project is also gratefully acknowledged. We are grateful to the two anonymous reviewers and editor for their insightful comments on an earlier version of this manuscript.

\section{References}

Cassman KG, Dobermann A, Walters DT (2002) Agroecosystems, nitrogen-use efficiency, and nitrogen management. Ambio 31:132-140. doi:10.1639/0044-7447(2002)031[0132:anuean]2.0.co;2

Guo J et al (2010) Significant acidification in major Chinese croplands. Science 327:1008-1010

Keating BA et al (2003) An overview of APSIM, a model designed for farming systems simulation. Eur J Agron 18:267-288

Liu L, Wang E, Zhu Y, Tang L (2012) Contrasting effects of warming and autonomous breeding on single-rice productivity in China Agriculture. Ecosyst Environ 149:20-29

Liu L, Zhu Y, Tang L, Cao W, Wang E (2013) Impacts of climate changes, soil nutrients, variety types and management practices on rice yield in East China: a case study in the Taihu region. Field Crop Res 149:4048

Lobell DB, Hammer GL, McLean G, Messina C, Roberts MJ, Schlenker W (2013) The critical role of extreme heat for maize production in the United States. Nat Clim Chang 3:497-501

Peng S et al (2006) Strategies for overcoming low agronomic nitrogen use efficiency in irrigated rice systems in China. Field Crop Res 96:37-47

Peng S et al (2004) Rice yields decline with higher night temperature from global warming. Proc Natl Acad Sci U S A 101:9971-9975

Prescott J (1940) Evaporation from a water surface in relation to solar radiation. Trans R Soc S Aust 64:114-118

Sheehy JE, Mitchell P, Ferrer AB (2006) Decline in rice grain yields with temperature: models and correlations can give different estimates. Field Crop Res 98:151-156

Tao F et al (2014) Responses of wheat growth and yield to climate change in different climate zones of China, 1981-2009. Agric For Meteorol 189:91-104

Tao F, Zhang Z, Zhang S, Zhu Z, Shi W (2012a) Response of crop yields to climate trends since 1980 in China. Clim Res 54:233-247

Tao F, Zhang S, Zhang Z (2012b) Spatiotemporal changes of wheat phenology in China under the effects of temperature, day length and cultivar thermal characteristics. Eur J Agron 43:201-212

Timsina J, Humphreys E (2006) Performance of CERES-Rice and CERES-Wheat models in rice-wheat systems: a review. Agric Syst 90:5-31

Wang J, Wang E, Yang X, Zhang F, Yin H (2012) Increased yield potential of wheat-maize cropping system in the North China Plain by climate change adaptation. Clim Chang 113:825-840

Wei X, Zhang Z, Shi P, Wang P, Chen Y, Song X, Tao F (2015) Is yield increase sufficient to achieve food security in china? PloS One 10

Wiesmeier M, Hübner R, Kögel-Knabner I (2015) Stagnating crop yields: an overlooked risk for the carbon balance of agricultural soils? Sci Total Environ 536:1045-1051

Xiao D, Tao F (2014) Contributions of cultivars, management and climate change to winter wheat yield in the North China Plain in the past three decades. Eur J Agron 52:112-122

Xiong W, Holman IP, You L, Yang J, Wu W (2014) Impacts of observed growing-season warming trends since 1980 on crop yields in China. Reg Environ Chang 14:7-16

Zhang T, Zhu J, Wassmann R (2010) Responses of rice yields to recent climate change in China: an empirical assessment based on long-term observations at different spatial scales (1981-2005). Agric For Meteorol 150: $1128-1137$

Zhang X, Wang S, Sun H, Chen S, Shao L, Liu X (2013) Contribution of cultivar, fertilizer and weather to yield variation of winter wheat over three decades: a case study in the North China Plain. Eur J Agron 50:52-59 